\title{
Mapping language dominance through the lens of the Wada test
}

\author{
Bornali Kundu, MD, PhD, John D. Rolston, MD, PhD, and Ramesh Grandhi, MD \\ Department of Neurosurgery, Clinical Neurosciences Center, University of Utah, Salt Lake City, Utah
}

The sodium amytal test, or Wada test, named after Juhn Wada, has remained a pillar of presurgical planning and is used to identify the laterality of the dominant language and memory areas in the brain. What is perhaps less well known is that the original intent of the test was to abort seizure activity from an affected hemisphere and also to protect that hemisphere from the effects of electroconvulsive treatment. Some 80 years after Paul Broca described the frontal operculum as an essential area of expressive language and well before the age of MRI, Wada used the test to determine language dominance. The test was later adopted to study hemispheric memory dominance but was met with less consistent success because of the vascular anatomy of the mesial temporal structures. With the advent of functional MRI, the use of the Wada test has narrowed to application in select patients. The concept of selectively inhibiting part of the brain to determine its function, however, remains crucial to understanding brain function. In this review, the authors discuss the rise and fall of the Wada test, an important historical example of the innovation of clinicians in neuroscience.

https://thejns.org/doi/abs/10.3171/2019.6.FOCUS19346

KEYWORDS Wada test; language dominance; laterality; memory; epilepsy

The removal of a tumor at the cost of the patient's speech is scarcely an accomplishment on which to congratulate oneself.

\section{- W. James Gardner, American neurosurgeon ${ }^{8}$}

Paul Broca (Fig. 1) published the earliest anatomical evidence that language function localized to the left frontal lobe in the posterior part of the third convolution (Fig. 2), now known as "Broca's area." 3,7 Broca arrived at his theory based on clinical examinations and subsequent cortical damage found on autopsy. Approximately 80 years later, W. James Gardner (Fig. 3), ${ }^{21}$ an American neurosurgeon practicing at the Cleveland Clinic, was the first to report the use of subdural anesthetic injections to distinguish language lateralization in individual patients for the purposes of surgical planning for cortical resections. $\mathrm{He}$ ascribed to the prevailing theory at the time that language "dominance" (or the structurally essential areas of cortex to support language function, expressive language in particular) generally occurred on the contralateral side to the dominant hand. In the case of left-handed persons, determination of laterality of language dominance was more complex. Left-handedness was thought to be deter- mined by family history or could be "acquired" secondary to brain injury. ${ }^{26}$ Gardner reported two cases in which the patients were left-handed, and he reasoned that should anesthetic injection not result in aphasia, the patient probably had contralateral language dominance. He injected procaine hydrochloride into the subdural space via a burr hole to create temporary lesions. ${ }^{8}$ In his paper, Gardner described a male patient who was born left-handed with a presumed right-sided language dominance and a known right-sided brain lesion. He injected the anesthetic into the subdural space over the right side of the brain and found no language deficits, allowing him to resect the lesion on the right safely and without any postoperative deficits. He also reported on his experience with a female patient with seizures who had a presumed brain injury from scarlet fever in infanthood and right-sided hemiplegia leading to "acquired" left-handedness. He injected procaine via a burr hole over the patient's left hemisphere with no resultant aphasia, which he took to mean that she had truly acquired right-sided language dominance. He then resected the left frontal operculum (Broca's area) and part of the left motor cortex with no consequent postoperative aphasia.

ABBREVIATIONS ECT = electroconvulsive therapy; $\mathrm{fMRI}=$ functional MRI; ICA = internal carotid artery; $M T L=$ mesial temporal lobe; PCA = posterior cerebral artery. SUBMITTED May 1, 2019. ACCEPTED June 14, 2019. INCLUDE WHEN CITING DOI: 10.3171/2019.6.FOCUS19346. 


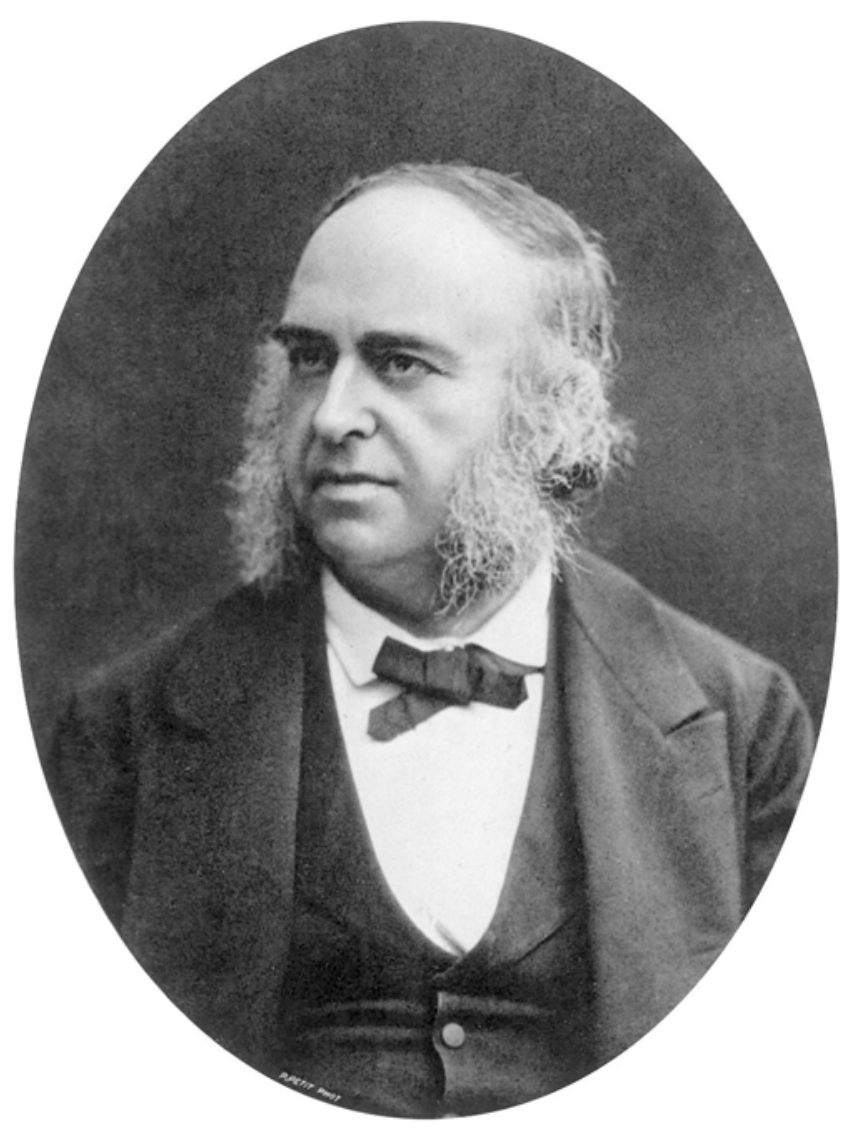

FIG. 1. A portrait of Pierre-Paul Broca. CC BY 4.0 (https:// creativecommons.org/licenses/by/4.0/legalcode). Available at https:// wellcomecollection.org/works/gmu58arz.

\section{Development of the Wada Test}

The sodium amytal test, or Wada test, named after Juhn A. Wada (Fig. 4), a Japanese-born neurologist, has remained an essential piece of presurgical planning. A key contribution of the Wada test was to yield a better understanding of language dominance in the age before MRI. It continues to be used to identify the laterality of language and memory areas in the brains of individual patients. What is less commonly known is that Wada originally proposed the test in hopes of protecting the left side of the brain from the effects of frontal electroconvulsive therapy (ECT) or pentylenetetrazol treatment in the 1940s.

ECT was being used broadly in the 1940s to treat psychiatric illnesses, including psychoses and major depression, but it resulted in generalized convulsions and cognitive impairment. ${ }^{26}$ After observing patients and noting their postprocedural deficits after ECT, Wada postulated that the electrodes should be placed over the nondominant hemisphere, thus sparing the dominant hemisphere and mitigating language deficits and amnesia. ${ }^{31}$ It was known that frontally placed ECT electrodes caused language deficits and seizures, while stimulation via pre-auricular electrodes caused amnesia. Wada wondered about the mechanism of these convulsions and whether there was a way to stop the seizures from generalizing, thus arriving at the concept of anesthetizing half of the brain during ECT. He hoped to use sodium amytal, a new barbiturate that had become available in the US, as well as Japan, to protect the left hemisphere during these procedures.

This suggestion of using sodium amytal was initially met with much criticism from the medical community; however, Wada described a "fateful encounter" that led to his publication of the modern Wada test. ${ }^{30,31}$ He was asked to treat a young male Japanese cook with status epilepticus secondary to a gunshot wound to the head (inflicted by a drunk US soldier who had claimed he could shoot off the cook's hat). The symptoms were refractory to all antiepileptic drugs available, and so, with the family's consent, Wada administered a 10\% sodium amytal injection via direct carotid artery puncture and stopped the seizures. The patient subsequently experienced hemiplegia and speech arrest for several minutes, which Wada described as a "hair-raising" moment in his account "A fateful encounter: sixty years later-reflections on the Wada test." ${ }^{30}$ Soon after, the patient recovered motor and language functions. After this initial case, Wada studied the effects of sodium amytal more closely and published his original paper describing the technique as a means of ascertaining language dominance in patients in 1949. In his work, Wada detailed the effects of sodium amytal in the evaluation of nonhuman primates and in 20 epilepsy patients. During each patient's procedure, the patient was asked to hold up both arms and count backward as 150-200 mg of $10 \%$ sodium amytal solution was injected over several seconds into the internal carotid artery (ICA) (Fig. 5). Within seconds, there was hemiplegia, and, if the ICA supplied the dominant hemisphere, there was speech arrest. Function was regained within minutes. During the time of anesthetic perfusion, the patient underwent rapid neuropsychiatric testing of language and memory functions. After one ICA was injected, the contralateral vessel was injected in a similar manner, usually the next day. This procedure is largely what is practiced today with adaptation of the location of arterial puncture, the neurocognitive tests used, the timing of the test in that the whole test is done in a single day, and the dosing of sodium amytal.

\section{Characterization and Validation of the Wada Test}

Wada eventually introduced his test to the Montreal Neurological Institute in 1955 and stayed in Canada to continue his practice. Brenda Milner, a well-known neuropsychologist at the Montreal Neurological Institute, explored the ability of the Wada test to discern language and memory functional dominance. The first large study to evaluate the Wada test was done by Branch et al. ${ }^{6}$ in 1964 : 123 patients were tested, and of those, 102 patients had epilepsy, while the rest had neoplasms of the brain, primarily meningiomas and gliomas. Only those patients for whom lateralization was unclear underwent the Wada test-mainly patients who were left-handed or ambidextrous. The authors reported that $48 \%$ of those patients had left-sided language dominance, $38 \%$ had right-sided dominance, and $14 \%$ had bilateral representation. Language performance was based on errors in counting, object naming, and the presence of paraphasic responses during serial speech, 
Prenons d'abord le premier cas, le cas Leborgne; il 's'agit, sans aucune discussion possible, d'une Aphasie de Broca, le malade n'a

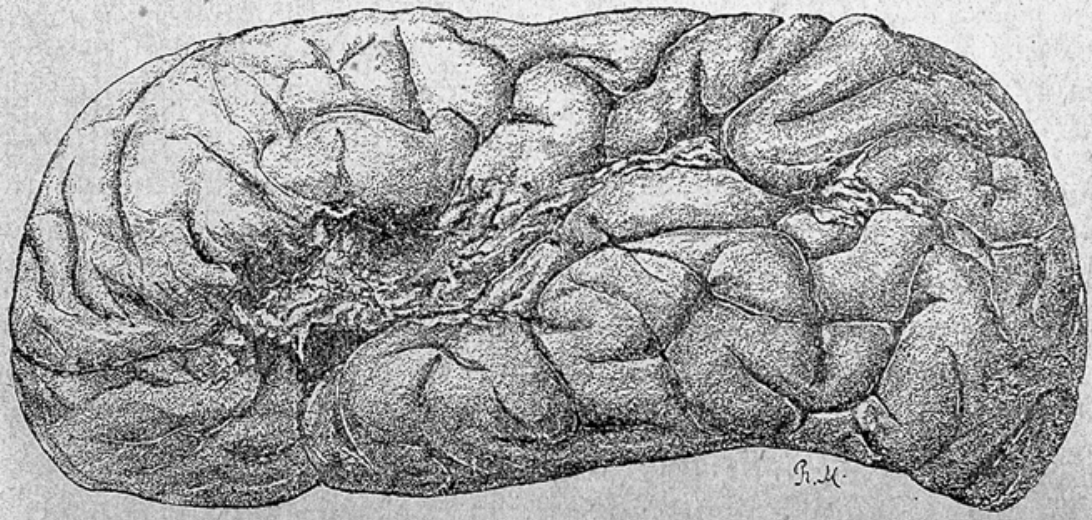

Fig. 1 - Hémisphère gauche du cerveau de Leborgne, première autopsie de Broca. Dessin fait sur la photographie de la pièce actuellement conservée au Musée Dupuytren. On voit que, en outre de la lésion de la troisième frontale, le ramollissement existait tout le long de la scissure de Sylvius et siégeait par conséquent aussi dans la zone de Wernicke.

plus à sa disposition que la syllabe tan, il est hémiplégique à droite, c'est un aphasique typique.

Voyons les données de l'autopsie ;

FIG. 2. A drawing of Louis Victor ("Tan") Lebourgne's brain after the patient's death. There is necrosis of the area of the left frontal operculum. Pierre Marie, Travaux et memoires. Credit: Wellcome Collection. CC BY 4.0 (https://creativecommons.org/licenses/ by/4.0/legalcode). Available at https://wellcomecollection.org/works/vyfjw978.

such as errors in reciting days of the week. Initial validation was done using results from intraoperative stimulation mapping and postoperative aphasia in patients, ${ }^{6}$ with 43 of 44 patients having confirmation of lateralization of the predicted dominant hemisphere via electrical stimulation mapping and 45 of 46 patients who had undergone surgery on the nondominant hemisphere having no speech arrest with stimulation mapping. Of note, Loring et al..$^{12}$ later incorporated comprehension into the Wada test battery in the form of following complex commands.

\section{Further Refinement of Understanding Bilateral Representation of Language Using Wada Testing}

The relationship between brain injury and the "shift" in language dominance and handedness continued to be studied in the 1980s using the Wada test. Strauss and Wada $^{29}$ demonstrated a relationship between age of injury onset and language laterality such that only $36 \%$ of those with left-hemisphere injury or seizures before the age of 1 maintained left-hemisphere language dominance. By contrast, $86 \%$ of patients with damage to the left side after 1 year of age had left-sided language dominance. The question of whether handedness and language dominance shift without overt hemiplegia was further explored by Woods et al. ${ }^{34}$ who reported their experience in 273 patients who underwent Wada testing. They found that among non- hemiparetic patients with extratemporal lesions, left-handed patients were more likely to have atypical dominance than right-handed patients. The authors suggested that, after a brain injury, handedness and language dominance may shift, although the causality cannot be known.

Loring et al. ${ }^{15}$ were among the first to introduce the idea of a "forced relative dominance" by quantifying dominance through a lateralization index obtained during Wada testing: $(\mathrm{L}-\mathrm{R}) /(\mathrm{L}+\mathrm{R})$, where $\mathrm{L}$ is the language score obtained after sodium amytal administration into the right ICA and $\mathrm{R}$ is the language score obtained after sodium amytal administration into the left ICA. Scores of $>0.15$ or $<-0.15$ were categorized into left- or rightdominant patients. Scores between 0.15 and -0.15 were classified as bilateral dominance. The language score was based on multiple language assessments, including counting, sequencing, and comprehension. The determination of the lateralization index significantly decreased the number of patients initially believed to have bilateral language dominance. ${ }^{12}$ In the modern era, the concept of the lateralization index has been used with functional MRI (fMRI) to qualify the symmetry of language-related blood oxygen-dependent activation. ${ }^{4,5}$

\section{Use of Wada Testing for Establishing Mnemonic Dominance}

The utility in the Wada test for discerning memory 


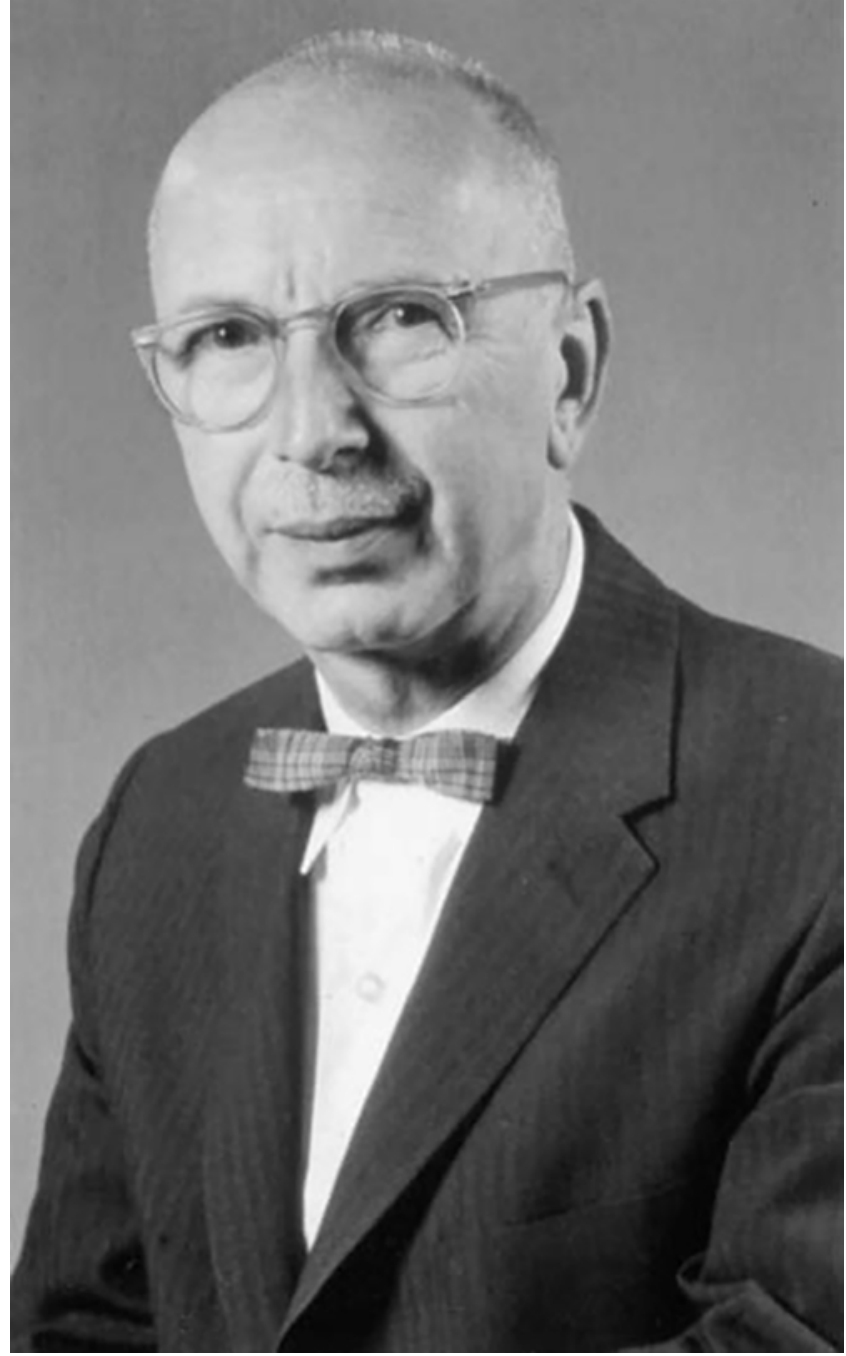

FIG. 3. A photograph of Dr. W. James Gardner. Reprinted with permission, Cleveland Clinic Center for Medical Art \& Photography, (C) 1958. All rights reserved.

dominance has yielded mixed results. In the 1950s, Wilder Penfield, William Scoville, Maitland Baldwin, and A. Earl Walker were notable neurosurgeons who performed temporal lobectomies to treat mesial temporal lobe (MTL) epilepsy and noted that the mesial temporal structures were important for long-term memory formation. . $22,25,32^{2}$ The surgeons observed a spectrum of temporary and permanent memory deficits after resection, but the surgery generally spared skill learning and other aspects of cognitive control. ${ }^{20}$ Furthermore, Milner, Penfield, and Scoville $^{18,20,22,25}$ noted an increase in postoperative memory impairment in cases of bilateral dysfunction of the temporal lobes (i.e., in patients whose seizure focus was localized to one MTL but with concomitant atrophy of the contralateral MTL) and postulated that the contralateral MTL perhaps could not support memory function. Thus, in order to study memory dominance better, surgeons began to use the Wada test to discern memory support in each MTL. ${ }^{18}$

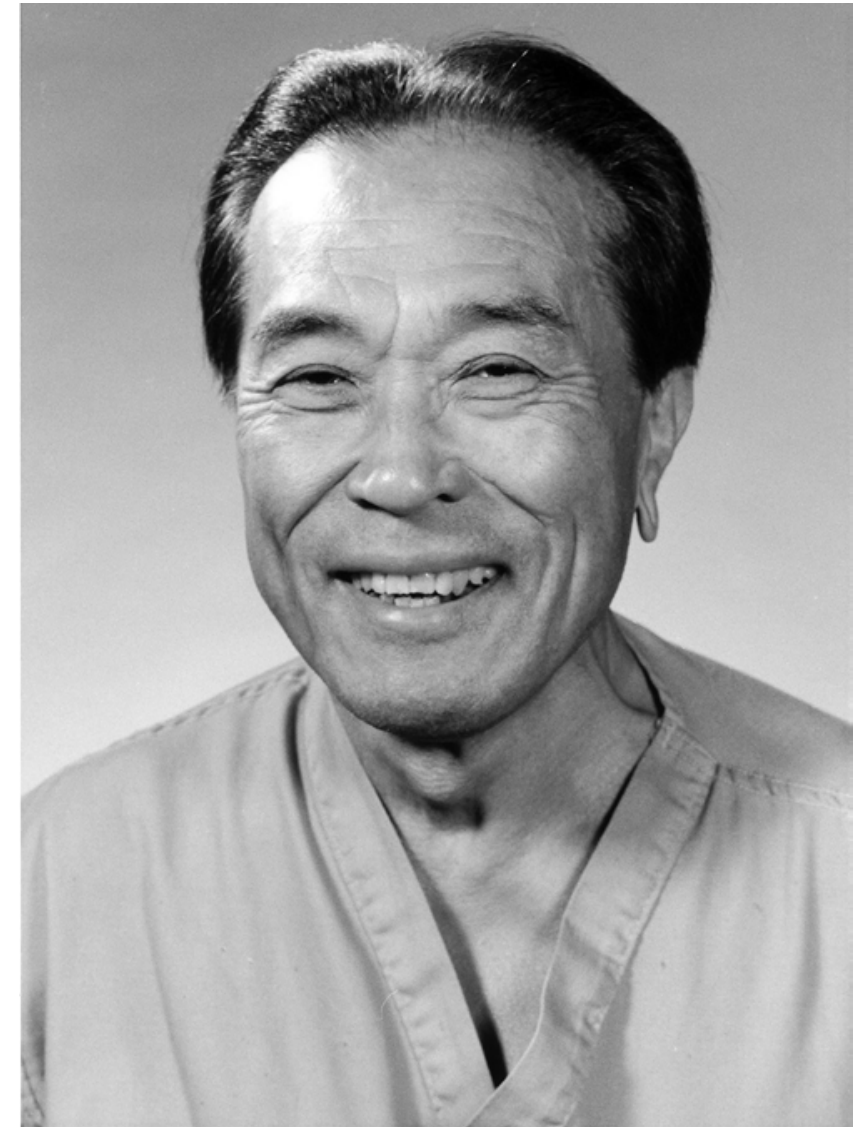

FIG. 4. A photograph of Dr. Juhn Wada. Courtesy of the University of British Columbia Archives (UBC44.1/3071).

For example, Milner et al. ${ }^{19}$ described a patient with bilateral seizure onset from the bilateral MTLs in whom a preoperative sodium amytal injection into the left ICA resulted in language deficits - implying left language dominance - and an injection into the right ICA elicited memory deficits-implying right MTL-based memory dominance. A resection of the patient's left MTL resulted in no postoperative memory deficits. A later variant of neurocognitive testing during sodium amytal injection involved showing two line drawings of objects before and after anesthetic injection and subsequently asking the patient to recall them after recovery of motor function. Milner considered this a particularly crucial test of anterograde amnesia because the injection anesthetized structures responsible for consolidating the memory and thus affecting memory formation. ${ }^{12}$ Milner did note, however, that there were inconsistencies in the testing that limited its validity; crucially, the initial studies with the Wada test did not incorporate a contrast dye control to assess for hippocampal perfusion prior to injecting anesthetic into the ICA. When hippocampal perfusion was confirmed, the memory testing results remained inconsistent, suggesting that memory mechanisms are likely distributed between hippocampi and perhaps even across areas of cortex such that ascribing sole memory function to a unilateral hippocampus is

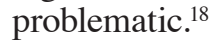




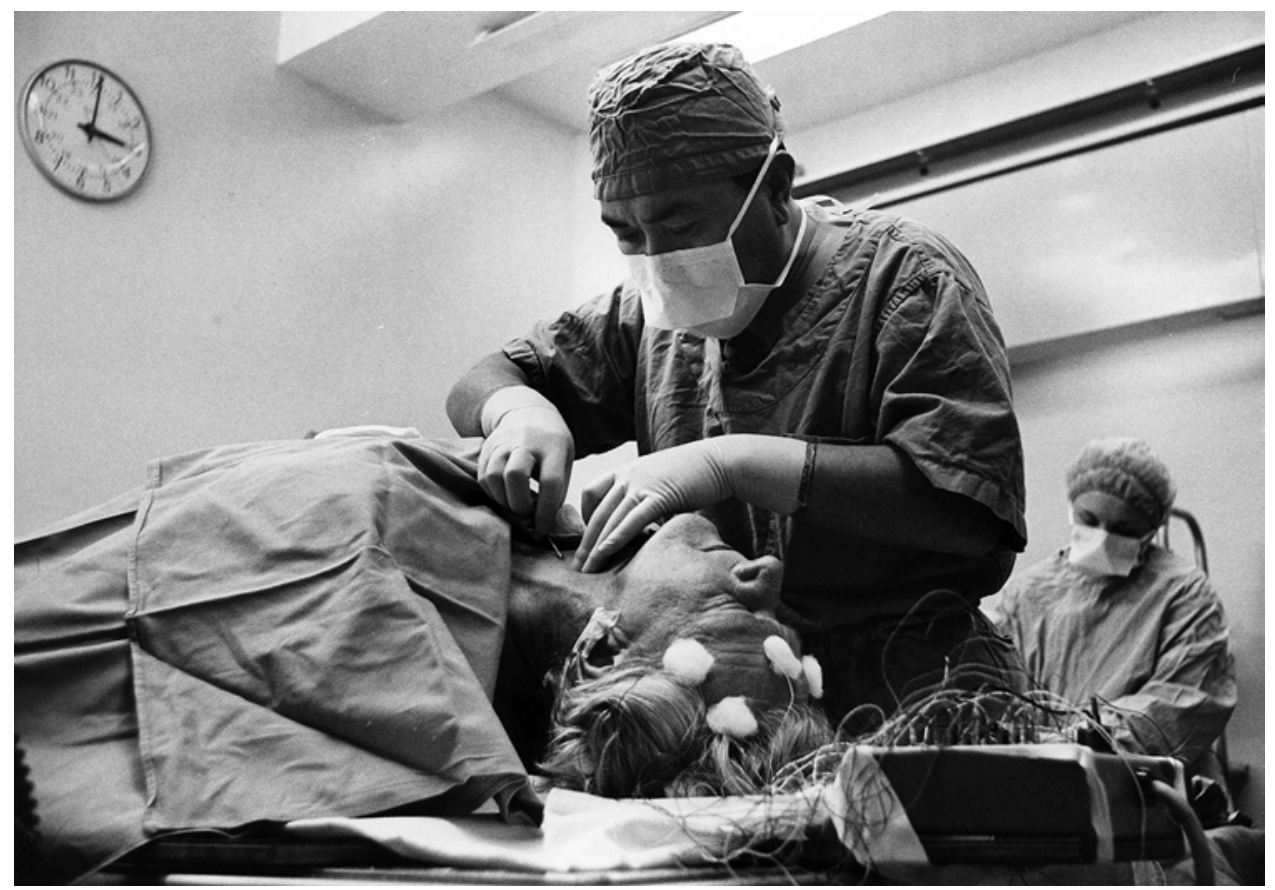

FIG. 5. Juhn Wada in the operating room performing a carotid artery puncture for injection of sodium amytal. Electroencephalography electrodes are attached to the scalp to monitor injection efficacy. Courtesy of University of British Columbia Archives (UBC41.1/2160).

Many reports have since been published showing that, despite positive Wada results for memory dominance, temporal lobectomy of the ipsilateral hemisphere demonstrates no appreciable postoperative memory deficits. ${ }^{13,14}$ One important confounder is that the predominant blood supply to MTL structures is from the posterior cerebral artery (PCA), which is not injected during routine Wada tests, and contralateral flow of sodium amytal through the anterior communicating artery. To help address this, more selective injections of sodium amytal have been performed including selective injections of the PCA. Thus, for example, Jack et al. ${ }^{10}$ showed that PCA-specific injections could target hippocampal structures to obtain the desired memory impairment.

\section{Other Cognitive Effects of the Wada Test}

Although they are not frequently reported in the literature, a range of extralinguistic and extramnemonic deficits follow sodium amytal injection into the ICAs. Attentional deficits after left- or right-sided injection have been tested with different types of stimulus presentation tasks. Huh et al. ${ }^{9}$ presented visual stimuli after amytal injection and found attentional lapses within the first several minutes of injection into either ICA but noted pronounced lapses after left-sided injections. Tactile neglect was more significant after right-sided injection compared with left. ${ }^{16}$ This observation was reproduced using a visual search task as well, with the results being consistent regardless of handedness and language dominance. ${ }^{27} \mathrm{In}$ deed, the belief that right-sided lesions produce neglect of the left and right side, while left-sided lesions produce neglect of only the right side, perhaps owing to its role in supporting language function, is a prevalent theory of attention. ${ }^{17,33}$

\section{Limitations of Wada Testing}

As a relatively invasive test, application of the Wada test is limited. Potential complications include encephalopathy, stroke, vessel dissection, and seizure. ${ }^{11}$ Additionally, it is difficult to repeat a Wada test, and the results are often not consistent on repetition, largely because of how the results are scored and then subsequently categorized into left, right, and bilateral dominance. ${ }^{12}$ Performing the cognitive tests after injection can be challenging because some patients may simply fall asleep and not be able to perform the tasks. Also, there are issues of cross flow within an individual patient that may render the Wada results uninterpretable.

\section{Advent of fMRI and the Decline in the Use of Wada Testing}

An international survey published in 2008 demonstrated a dramatic decline in the use of the Wada test in presurgical planning for patients with temporal lobe epilepsy over the preceding 15 years. ${ }^{2}$ The Wada test has been largely supplanted by fMRI testing, ${ }^{28}$ which is noninvasive and has good concordance with Wada results. ${ }^{4,5}$ Preoperative fMRI is sensitive and specific for predicting language-related outcomes such as naming deficits after anterior temporal lobectomy surgery. ${ }^{24}$ Additionally, asymmetry of fMRI activation in mesial temporal struc- 
tures during a delayed recognition task has been shown to be able to predict postsurgical cognitive outcomes. ${ }^{23}$

\section{Conclusions}

Understanding the cortical localization of language and memory in patients has remained a challenge for neuroscientists. The use of injectable anesthetics to better delineate language function and mitigate surgical risk has been an important development for neurosurgical practice. Although utilization of the Wada test has decreased since the advent of fMRI, it remains an essential tool in the evaluation of select patients with epilepsy. As Juhn Wada himself commented regarding its use in evaluating patients for MTL surgery, "while we await the arrival of validated safe alternative(s), judicious and innovative use of the carotid amytal deactivation by a skilled hand, when justified, can not only continue to help patients but also create new information and hypotheses on the mechanism of function and dysfunction of the human brain in the behavioral state." 30 Thus, continued improvement in agents and techniques to aid in determining language dominance and memory localization will not only provide help to those with epilepsy but potentially contribute significantly to our understanding of neuroanatomy and functional neuroscience.

\section{Acknowledgments}

Funding sources: NIH NCATS KL2 TR002539 and NREF Neurosurgical Research Fellowship Grant.

\section{References}

1. Baldwin M: [Unexpected mental modifications after subtotal temporal lobectomy.] Neurochirurgie 2:152-167, 1956 (French)

2. Baxendale S, Thompson PJ, Duncan JS: The role of the Wada test in the surgical treatment of temporal lobe epilepsy: an international survey. Epilepsia 49:715-725, 2008

3. Berker EA, Berker AH, Smith A: Translation of Broca's 1865 report. Localization of speech in the third left frontal convolution. Arch Neurol 43:1065-1072, 1986

4. Binder JR: Functional MRI is a valid noninvasive alternative to Wada testing. Epilepsy Behav 20:214-222, 2011

5. Binder JR, Swanson SJ, Hammeke TA, Morris GL, Mueller WM, Fischer M, et al: Determination of language dominance using functional MRI: a comparison with the Wada test. Neurology 46:978-984, 1996

6. Branch C, Milner B, Rasmussen T: Intracarotid sodium amytal for the lateralization of cerebral speech dominance: observations in 123 patients. J Neurosurg 21:399-405, 1964

7. Broca P: Sur le siège de la faculté du langage articulé. Bull la Société d'Anthropologie Paris 6:377-393, 1865

8. Gardner WJ: Injection of procaine into the brain to locate speech area in left-handed persons. Arch Neurol Psychiatry 46:1035-1038, 1941

9. Huh K, Meador KJ, Loring DW, Lee GP, Brooks BS: Attentional mechanisms during the intracarotid amobarbital test. Neurology 39:1183-1186, 1989

10. Jack CR Jr, Nichols DA, Sharbrough FW, Marsh WR, Petersen RC, Hinkeldey NS, et al: Selective posterior cerebral artery injection of amytal: new method of preoperative memory testing. Mayo Clin Proc 64:965-975, 1989

11. Loddenkemper T, Morris HH, Möddel G: Complications during the Wada test. Epilepsy Behav 13:551-553, 2008
12. Loring D, Meador K, Lee G, King D: Amobarbital Effects and Lateralized Brain Function: The Wada Test. New York: Springer-Verlag, 1992

13. Loring DW, Lee GP, Flanigin HF, Meador KJ, Smith JR, Gallagher BB, et al: Verbal memory performance following unilateral electrical stimulation in human hippocampus. J Epilepsy 1:79-85, 1988

14. Loring DW, Lee GP, Meador KJ, Flanigin HF, Smith JR, Figueroa RE, et al: The intracarotid amobarbital procedure as a predictor of memory failure following unilateral temporal lobectomy. Neurology 40:605-610, 1990

15. Loring DW, Meador KJ, Lee GP, Murro AM, Smith JR, Flanigin HF, et al: Cerebral language lateralization: evidence from intracarotid amobarbital testing. Neuropsychologia 28:831-838, 1990

16. Meador KJ, Loring DW, Lee GP, Brooks BS, Thompson EE, Thompson WO, et al: Right cerebral specialization for tactile attention as evidenced by intracarotid sodium amytal. Neurology 38:1763-1766, 1988

17. Miller EK, Cohen JD: An integrative theory of prefrontal cortex function. Annu Rev Neurosci 24:167-202, 2001

18. Milner B: Amobarbital memory testing: some personal reflections. Brain Cogn 33:14-17, 1997

19. Milner B, Branch C, Rasmussen T: Study of short-term memory after intracarotid injection of sodium amytal. Trans Am Neurol Assoc 87:224-226, 1962

20. Milner B, Penfield W: The effect of hippocampal lesions on recent memory. Trans Am Neurol Assoc (80th Meeting):42-48, 1955-1956

21. Nathoo N, Mayberg MR, Barnett GH: W. James Gardner: pioneer neurosurgeon and inventor. J Neurosurg 100:965973, 2004

22. Penfield W, Milner B: Memory deficit produced by bilateral lesions in the hippocampal zone. AMA Arch Neurol Psychiatry 79:475-497, 1958

23. Rabin ML, Narayan VM, Kimberg DY, Casasanto DJ, Glosser G, Tracy JI, et al: Functional MRI predicts postsurgical memory following temporal lobectomy. Brain 127:2286-2298, 2004

24. Sabsevitz DS, Swanson SJ, Hammeke TA, Spanaki MV, Possing ET, Morris GL III, et al: Use of preoperative functional neuroimaging to predict language deficits from epilepsy surgery. Neurology 60:1788-1792, 2003

25. Scoville WB, Milner B: Loss of recent memory after bilateral hippocampal lesions. J Neurol Neurosurg Psychiatry 20:11-21, 1957

26. Snyder PJ, Harris LJ: The intracarotid amobarbital procedure: an historical perspective. Brain Cogn 33:18-32, 1997

27. Spiers PA, Schomer DL, Blume HW, Kleefield J, O'Reilly G, Weintraub S, et al: Visual neglect during intracarotid amobarbital testing. Neurology 40:1600-1606, 1990

28. Springer JA, Binder JR, Hammeke TA, Swanson SJ, Frost JA, Bellgowan PS, et al: Language dominance in neurologically normal and epilepsy subjects: a functional MRI study. Brain 122:2033-2046, 1999

29. Strauss E, Wada J: Lateral preferences and cerebral speech dominance. Cortex 19:165-177, 1983

30. Wada JA: A fateful encounter: sixty years later-reflections on the Wada test. Epilepsia 49:726-727, 2008

31. Wada JA: Youthful season revisited. Brain Cogn 33:7-10, 1997

32. Walker AE: Recent memory impairment in unilateral temporal lesions. AMA Arch Neurol Psychiatry 78:543552,1957

33. Weintraub S, Mesulam MM: Right cerebral dominance in spatial attention. Further evidence based on ipsilateral neglect. Arch Neurol 44:621-625, 1987

34. Woods RP, Dodrill CB, Ojemann GA: Brain injury, 
handedness, and speech lateralization in a series of amobarbital studies. Ann Neurol 23:510-518, 1988

\section{Disclosures}

Dr. Rolston has consulting agreements for NeuroPace and Medtronic.

\section{Author Contributions}

Conception and design: Grandhi, Kundu. Drafting the article: Kundu. Critically revising the article: all authors. Reviewed sub- mitted version of manuscript: all authors. Approved the final version of the manuscript on behalf of all authors: Grandhi.

\section{Correspondence}

Ramesh Grandhi: University of Utah, Salt Lake City, UT. neuropub@hsc.utah.edu. 